\title{
$\mathrm{JET}$ 기반 우회 경로 방식의 광 버스트 스위치 네트워크에서 동적 파장 할당과 선취권 방식에 의한 상대적 서비스 차별화 방안
}

\author{
백정훈*
}

\section{Relative Service Differentiation with Dynamic Wavelength Allocations and Preemptions in JET based Optical Burst-Switched Networks with Deflection Routing}

\author{
Junghoon Paik*
}

요 약

본 논문은 우회경로를 적용하는 JET 스위칭 방식의 광 버스트 스위치 네트워크에서 클래스간 비율적 서비스 차별 화 방안을 제안한다. 제안하는 방식은 동적파장할당, 선취권, 그리고 우회경로 방식을 적용한다. 동적파장할당은 주 기적인 측정을 통해 클래스간 손실 비율의 조정이 요구되는 경우에 높은 클래스에 할당된 파장의 수를 동적으로 증가 시킴으로서 높은 클래스의 손실률도 낮추면서 동시에 상대적 손실 비율도 유지한다. 가용한 파장이 모두 사용된 경우 에는 낮은 클래스의 트래픽이 사용하던 파장을 높은 클래스의 트래픽에 이양하는 선취권 방식을 적용한다. 동시에 우 회경로를 적용하여 높은 클래스나 낮은 클래스의 손실률을 낮춘다. 제안된 방식에 대한 큐잉 기반의 분석 모델이 도출 되고, 도출된 모델을 기반으로 성능분석을 수행하여 제안모델이 비율적 서비스 차별화를 제공함을 입증한다.

\section{ABSTRACT}

In this paper, relative service differentiation in JET based optical burst-switched networks with deflection routing is presented. It differs from conventional schemes in that it tries to make the loss rate of high class bursts as low as possible while maintaining the desired proportional ratio between the high class bursts and low class bursts. Strategies applied to it are dynamic wavelength allocation and the preemption which are combined to deflection routing. With dynamic wavelength allocation, the number of wavelengths allocated to high class bursts are dynamically changed. Preemption which gives more preference to high class bursts is also applied to decrease its loss rate. To lower the loss rate, deflection routing is applied for any kind of traffic. With those strategies, the suggested scheme shows desired properties that the loss rate of high class traffic is as lowered as possible. A queueing model for the scheme is developed to approximate loss ratio and the numerical results show that the proposed scheme provisions relative service differentiation.

\section{키워드}

$\mathrm{JET}$, 광 버스트 스위치, 우회경로, 선취권, 비례적 서비스 차별화

Key word

JET, Optical Burst Switch, Preemption, Proportional Service Differentiation

* 정회원 : 동아방송예술대학교(jhpaik@dima.ac.kr)

접수일자 : 2012. 04. 19

심사완료일자 : 2012. 06. 25

\section{Open Access http://dx.doi.org/10.6109/jkiice.2012.16.9.1906}

(c) This is an Open Access article distributed under the terms of the Creative Commons Attribution Non-Commercial License(http://creativecommons.org/li-censes/by-nc/3.0/) which permits unrestricted non-commercial use, distribution, and reproduction in any medium, provided the original work is properly cited. 


\section{I. 서 론}

네트워크가 전광화(all optical)되면서 새로운 교환 방 식인 Optical Burst Switching(OBS)이 제안되었다[1]. $\mathrm{OBS}$ 에서는 발신지와 착신지가 동일한 데이터 패킷 (packet)들이 엑세스(access) 교환기에서 서로 묶여져서 버스트(burst)로 구성된다. 버스트는 헤더(header)와 페 이로드(payload)로 구성되며, 헤더는 페이로드 보다 우 선 전송되어 목적지까지의 경로(path)에 놓여지는 교환 기의 자원을 예약하는 기능을 수행한다. 이 과정에서 스 위치에 요청되는 자원, 즉 파장(wavelength)이 가용하다 면 페이로드는 투명하게 다음 장치로 전달된고 그렇지 않다면 페이로드는 블록(block) 된다.

$\mathrm{OBS}$ 에 적용되는 파장 예약 방식으로 Just-in-time (JIT)[2], just-enough-time(JET)[3], burst segmentation (BS)[4] 등이 있다. JET 방식에서는 전송할 버스트를 갖 고 있는 송신 노드는 우선적으로 목적지 노드까지 시그 널링(signaling) 채널을 통해 제어 패킷(control packet)을 송신한다. 송신된 제어 패킷은 뒤따를 버스트를 위해 목 적지까지의 데이터 경로를 설정하는 기능을 수행한다. 즉, 제어 패킷에 포함되는 라우팅 정보에 근거하여 경로 상의 각 노드에서는 출력 링크상의 가용한 파장을 선택 하여 예약한다. 이러한 기능이 수행되는 동안 버스트는 송신 노드에서 오프셋(offset) 타임동안 대기한다. 오프 셋 타임이 지나면 버스트는 설정된 경로를 통해 목적지 까지 전송된다.

OBS 네트워크에서는 다수의 버스트가 출력링크의 한 파장을 사용하기 위한 경합이 발 생할 수 있다. 제안된 경합제어 방식으로는 파장변환(wavelength conversion) [5],[6], fiber delay line(FDL) buffering[7], 우회경로 (deflection routing)[8],[9] 방식 등이 있다.

서비스 차별화(service differentiation)는 OBS 방식의 네트워크에서도 반드시 구비되어야 하는 핵심 기능이 며 일반적으로 절대적(absolute) 방식과 상대적(relative) 방식으로 구분된다. 절대적 차별화 방식은 손실률과 같 은 성능인자의 품질 상한선을 보장하는[10] 반면에 상대 적 차별화 방식은 트래픽의 특성과 중요도에 따라 트래 픽을 클래스(class)화 하고 클래스가 높을수록 상대적으 로 우수한 서비스 품질을 제공하는 방식이다[11], [12]. [10]에서는 early dropping mechanism과 파장 그룹화 방 식을 통해 비보장형(non-guaranteed) 트래픽의 손실률은
줄이면서 보장형(guaranteed) 트래픽의 손실률을 절 대적 으로 보장하는 방식을 제안한다. [12]에서는 우선순위가 높은 클래스의 버스트에는 낮은 클래스의 버스트보다 큰 오프셋 타임을 부여하는 방식으로 상대적 차별화 기 능을 제공한다. 오프셋 타임이 클수록 충돌 확률이 낮기 때문에 우선순위가 높은 클래스의 버스트일수록 오프 셋을 크게한다. 이 방식을 적용하면 상대적으로 우선순 위가 높은 클래스의 손실률은 낮아지는 반면에 우선순 위가 높은 클래스의 손실률은 높아지므로 상대적 서비 스 차별화 기능이 구현된다. [12]에서 도출된 정량적 성 능 지표를 보면 95[\%]의 두 클래스간 분리도(degree of isolation)를 달성하기 위해서는 $3 \bar{L}$ 의 여분의 오프셋이 요구된다. $\bar{L}$ 는 우선순위가 낮은 클래스 트래픽의 버스 트 길이를 의미한다. 사전에 설정된 클래스간 성능지표 비율을 유지하기 위하여 의도적으로 버스트를 폐기시 키는 방식이 [13]에서 제안된다. 이 방식에서는 가용한 채널의 존재 여부에 상관없이 사전에 설정된 비율이 위 반되면 의도적으로 버스트를 폐기시키므로 과도한 손 실률이 발생되는 단점을 갖는다. [14]에서는 단일 성능 지표가 아닌 다수 성능 지표를 처리할 수 있는 스케쥴러 (scheduler)를 사용하는 상대적 차별화 방식을 제안하고 있고, [15]에서는 확률적 방식으로 낮은 우선순위의 버 스트를 선취(preemption)하고 세그먼트(segment)하는 probabilistic preemptive burst segmentation (PPBS) 큐잉 (queueing) 모델을 제안한다. 또한 버스트 중 충돌이 발 생한 영역만을 폐기하여 상대적 서비스 차별화를 달성 하는 부분적 선취 방식이 제안된다[16].

상대적 서비스 차별화 방안에 있어서 가장 중요한 요 인은 우선순위가 높은 클래스 트래픽의 성능인자를 유 리하게 유지하는 것이다. 즉, 클래스간 성능 인자 비율을 유지하면서도 높은 클래스의 손실률이나 지연과 같은 성능품질을 가능한 한 높게 유지하여야 한다.

본 연구를 통해 우선순위가 높은 클래스의 성능인자 를 우수하게 유지하면서 낮은 클래스와의 상대적 성능 비율을 달성하는 방안을 제시하며 성능분석을 위해 [17] 에 기초한 큐잉 모델을 적용한다.

본 논문의 구성은 II 장에서 OBS 에 관한 일반적 내용 을 기술하고, III 장에서 제안하는 서비스차별화 방안을 다루고, IV 장에서 수학적 분석모델을 통한 성능분석 결 과를 제공하고 $\mathrm{V}$ 장을 통해 결론이 기술된다. 


\section{ПI. Optical Burst Switching}

\subsection{JET Signaling}

그림 1 은 JET의 기본 개념을 설명한다. 그림에서 전송 할 버스트를 갖고 있는 소스 노드는 목적지 노드로 시그 널링 채널을 통해 제어 패킷을 송신한다.

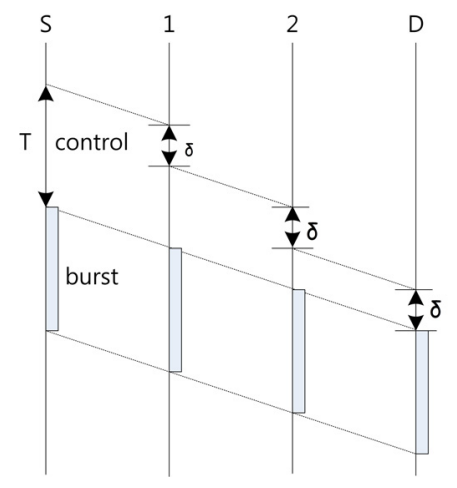

그림 1. JET 방식

Fig. 1 JET scheme

제어 패킷은 뒤따르는 버스트가 전송될 경로를 설정 하기 위하여 각각의 인접노드에서 처리된다. 즉, 제어패 킷에 포함되는 정보에 근거하여 각 노드는 출력링크상 의 가용한 파장을 선택하고 예약을 한 후 해당 버스트가 해당 출력링크의 출력파장을 사용하도록 스위치를 구 성한다. 스위치를 구성한 후 오프셋 시간 $\mathrm{T}$ 후에 버스트 는 예약된 파장을 통해 광 신호 형태로 전송된다. $\delta$ 를 각 노드에서 제어 패킷을 처리하고 노드를 구성하는데 소 요되는 최대 시간으로 정의하고 목적지까지의 경로에 높여지는 홉(hop) 수를 $h$ 라고 하면 오프셋 타임은 $\delta \times h$ 가 된다. 이러한 오프셋 타임의 설정으로 인해 각 노드에서 버스트가 도착하기 전에 제어패킷을 처리하 는데 필요한 충분한 시간을 갖게된다.

\section{2. 스위칭 시스템 구조}

그림 2는 일반화된 OBS 노드의 구조를 나타낸다. M 개의 입력 링크와 $\mathbf{M}$ 개의 출력 링크가 있고 각 링크에는 $\mathrm{W}$ 개의 파장이 다중화(multiplexed)된다. 제어패킷이 도 착하면 라우팅, 길이와 같은 정보를 포함하는 헤더 추출 을 위해 제어기(controller)에서 전기적으로 처리된다. 헤
더가 처리되는 동안 페이로드는 입력모듈의 FDL에 저 장된다. 제어기는 헤더정보를 기반으로 버스트가 전송 될 출력 화이버를 선택하고 스위치를 구성한다.

\section{III. 비례적 차별화}

\section{1. 비례적 차별화 모델}

비례적 차별화 모델에서는 손실률과 같은 $\mathrm{QoS}$ 성능 지표에 대하여 식 (1)과 같이 비례적으로 정량화된다. 만 일 $q_{i}$ 가 클래스 $\mathrm{i}$ 의 성능인자이고 $\alpha_{i}$ 가 상위 클래스 $\mathrm{i}+1$ 과 하위 클래스 $\mathrm{i}$ 간의 성능비율이라면 식 (1)은 어떤 조 건에서 언제라도 만족되어야 비례적 서비스 차별화가 제공된다고 할 수 있다.

$$
\frac{q_{i}}{q_{i+1}}=\alpha_{i}(i=1,,,, N-1)
$$

\section{2. 비례적 차별화 방식}

그림 2 는 $\left\{\lambda_{1}, \lambda_{2}, \ldots, \lambda_{W}\right\}$ 으로 표현되는 $\mathrm{W}$ 개의 파 장을 갖는 출력 링크에 대한 제안된 구조이다.

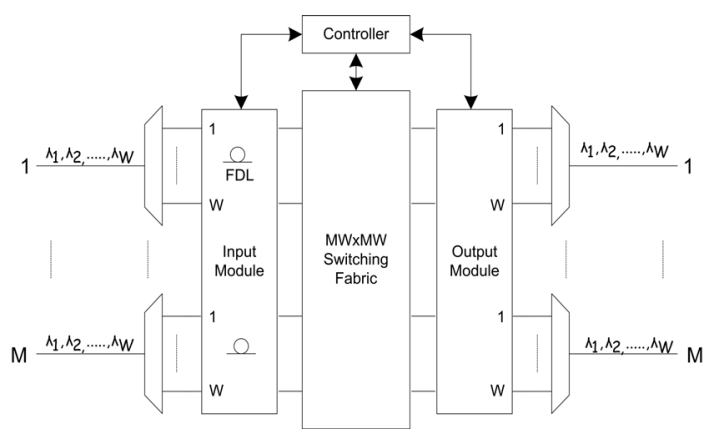

그림 2. $\mathrm{OBS}$ 스위칭 시스템 구조

Fig. 2 OBS Switching System Architecture

각각의 클래스 트래픽은 비우회(non-deflected)와 우 회(deflected) 트래픽으로 분류된다. 따라서, 높은 클래스 의 비우회 트래픽과 우회 트래픽, 낮은 클래스의 비우회 트래픽과 우회 트래픽으로 분류된다. 각 클래스의 우회 버스트에 대하여 오프셋 타임을 연장시키기 위한 버퍼 $V_{1, d}, V_{0, d}$ 가 각각 정의된다. 
$W$ 파장은 두 단계로 분리되어 처음 단계에는 $K$ 개 의 파장이 할애되고 두 번째 단계에는 $W-K$ 개의 파 장이 할당된다. 처음 단계의 $K$ 개의 파장은 높은 클래 스의 트래픽 버스트에 의해 전적으로 사용되고 나머지 $W-K$ 개의 파장은 처음 단계에서 서비스되지 못한 높은 클래스의 버스트와 낮은 클래스의 버스트에 의해 경합된다. $K$ 개의 파장은 상대적 차별화를 보장하기 위해 동적으로 가변된다. 즉, 버스트가 도착했을 때 식 (1)의 비율이 목표치 $\alpha_{i}$ 보다 적으면 $\alpha_{i}$ 는 증가되어야 한다. $\alpha_{i}$ 를 증가시키기 위해서는 높은 우선순위 클래 스의 손실률이 감소하거나 낮은 순위 클래스의 손실률 이 증가되어야 한다. $\mathrm{K}$ 개의 파장이 높은 클래스에 의 해 전적으로 사용되기 때문에 $\mathrm{K}$ 를 증가시킴으로서 높 은 순위 클래스의 손실률을 낮추고 동시에 낮은 클래스 의 손실률은 높게 된다. 동일한 논리를 적용하면 현재 의 손실률 비율이 목표치보다 높은 경우는 $\mathrm{K}$ 값을 낮추 면 된다.

$\mathrm{K}$ 값을 증가시키거나 감소시키는 것은 손실률에 큰 변화를 유발하는 것에 주목하여 목표-비율 정확도 계 수인 $\varepsilon$ 을 도입한다. 현재의 손실률 비율이 $\alpha_{i}-\varepsilon$ 보 다 적거나 $\alpha_{i}+\varepsilon$ 보다 크다면 이것은 목표 비율인 $\alpha_{i}$ 에서 크게 벗어나 있음을 의미하므로 $\alpha_{i}$ 로의 급격한 수렴이 요구된다. $\mathrm{K}$ 값의 변화는 손실률에 큰 영향을 미치므로 이 경우에는 $\mathrm{K}$ 값을 변화시켜 목표 비율에 근 접시킨다.

손실률 비율이 $\alpha_{i}-\varepsilon$ 보다 크고 $\alpha_{i}$ 보다 적은 경우 는 보다 정교한 조정이 요구되므로 $\mathrm{K}$ 값을 변화시키는 방식은 적용되지 않는다. 이 경우에도 손실률 비율은 증 가되어야 하므로 높은 클래스의 손실률은 낮아지거나 혹은 낮은 클래스의 손실률이 증가되어야 한다. 이러한 상황에서 입력되는 버스트가 높은 클래스의 트래픽인 경우 선취권이 적용되어 높은 클래스의 손실률을 낮추 고 동시에 낮은 클래스의 손실률을 높인다. 만일 모든 파 장이 높은 우선순위의 트래픽에 의해 사용 중이어서 선 취권이 불가한 경우는 우회를 시켜 높은 클래스의 손실 률을 낮춘다. 다른 경우로서 입력되는 트래픽이 낮은 우 선순위인 경우는 낮은 우선순위의 트래픽 손실률을 높 이기 위하여 의도적으로 폐기시킨다. 또한, 새로운 버스 트가 도착한 경우 손실률 비율이 $\alpha_{i}$ 보다 크고 $\alpha_{i}+\varepsilon$
보다 적은 경우는 손실률 비율은 감소되어야 한다. 손실 률 비율을 감소시키기 위해서는 낮은 우선순위의 클래 스는 낮아져야 하고 높은 우선순위의 클래스는 증가되 어야 한다. 이러한 상황에서 새로이 도착된 버스트가 높 은 우선순위인 경우는 우선순위 높은 트래픽의 손실률 을 높이기 위하여 의도적으로 폐기한다. 또한, 낮은 우선 순위의 트래픽이 도착했을 때 모든 파장이 사용 중인 경 우에는 우회를 적용하여 낮은 우선순위의 손실률을 낮 춘다.

위에서 기술한 내용에 대한 구현 방식은 아래와 같다.

$C_{k}$ : 도착하는 클래스 $\mathrm{k}$ 버스트의 수 $\alpha_{k}$ : 클래스 $\mathrm{k}+1$ 과 클래스 $\mathrm{k}$ 간의 목표 비율 $K$ : 상위 클래스에 할애되는 파장의 수 $D_{k}$ : 폐기되는 클래스 $\mathrm{k}$ 버스트의 수 $L_{k}=\frac{D_{k}}{C_{k}}$ : 클래스 $\mathrm{k}$ 의 버스트 손실률 $\varepsilon:$ 목표 비율 정확도 계수

$K \leftarrow W-1$

A burst $B_{k}$ arrives, $C_{k}++;$; if $\frac{L_{i}}{L_{i+1}}<\alpha_{i}-\varepsilon$ then $K++$; elseif $\frac{L_{i}}{L_{i+1}}>\alpha_{i}+\varepsilon$ then K-- ; elseif $\alpha_{i} \leq \frac{L_{i}}{L_{i+1}}<\alpha_{i}+\varepsilon$ then if $B_{k}$ is low class traffic then if deflection is possible then deflect it; end if;

elseif it is high class traffic then drop it $\left(D_{k}++\right)$;

no preemption;

end if;

elseif $\alpha_{i}-\varepsilon \leq \frac{L_{i}}{L_{i+1}} \leq \alpha_{i}$ then

if $B_{k}$ is high class traffic then 
if preemption is possible then preempt low class traffic $\left(D_{k-1}++\right)$

else

deflect it;

end if;

elseif it is low class traffic then

drop it $\left(D_{k}++\right)$;

end if;

end if;

\section{3. 수학적 분석}

제안한 $\mathrm{QoS}$ 방식에 대한 분석 모델을 개발하기 위하 여 그림 3 을 참조한다. 높은 클래스를 class1, 낮은 클래 스를 class0로 표기하며 다음의 가정을 한다.

- class1의 비우회 버스트의 평균 도착률을 $\gamma_{1, n}$, class1 의 우회 버스트 평균 도착률을 $\gamma_{1, d}$, class0의 비우회 버스트 평균 도착률을 $\gamma_{0, n}$, class0의 우회 버스트의 평균 도착률을 $\gamma_{0, d}$ 으로 표기하고 각각은 Poisson 분 포를 따른다.

- 우회 버스트의 평균 홉(hop) 수는 $h$ 이다.

- 각 홉에서 제어패킷의 평균처리 시간은 $\delta$ 이다.

- 버스트 길이는 지수 분포를 따르며 평균은 $L=1 / \mu$ 이다.

- 가상 $\mathrm{FDL}$ 인 $V_{o, d}, V_{1, d}$ 는 각각 class0 와 class1의 우 회 버스트를 저장하는데 사용한다.

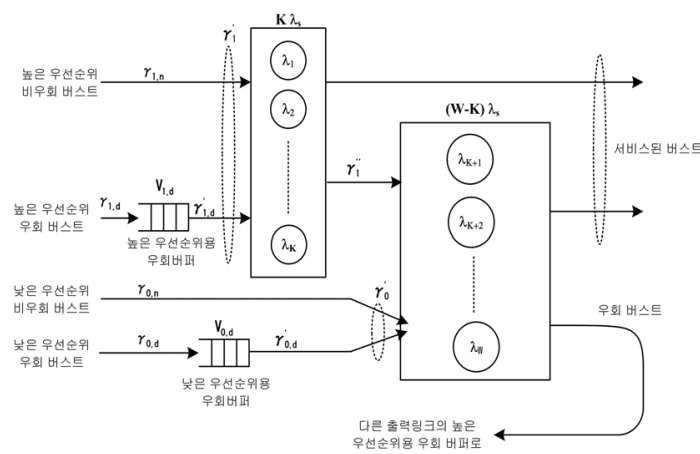

그림 3. 제안된 출력링크 구조 Fig. 3 Suggested Output Link Architecture
그림 3의 $\mathrm{FDL}$ 에서의 우회 버스트는 $\mathrm{M} / \mathrm{M} / \mathrm{c} / \mathrm{c}$ 큐잉모 델로 규정이 가능하고, 가상 $\mathrm{FDL}$ 인 $V_{o, d}, V_{1, d}$ 의 평균 서비스율은 $\mu_{d}=1 /(\delta \times h)$ 이므로 Erlang's loss formula에 의해 $V_{o, d}, V_{1, d}$ 에서의 손실률은 각각 식 (2) 와 (3)으로 주어진다.

$$
\begin{gathered}
p_{0, d}=\frac{\frac{\left(a_{0, d}\right)^{V_{0, d}}}{V_{0, d} !}}{\sum_{i=0}^{V_{0, d}} \frac{\left(a_{0, d}\right)^{i}}{i !}}, a_{0, d}=\frac{\gamma_{0, d}}{\mu_{d}} \\
p_{1, d}=\frac{\frac{\left(a_{1, d}\right)^{V_{1, d}}}{V_{1, d} !}}{\sum_{i=0}^{V_{1, d}} \frac{\left(a_{1, d}\right)^{i}}{i !}}, a_{1, d}=\frac{\gamma_{1, d}}{\mu_{d}}
\end{gathered}
$$

Markovian queue 에서 버퍼의 용량 한계에 제한이 없는 경우에는 서비스율의 분포는 도착률 분포와 동 일하므로 비록 $V_{0, d}, V_{1, d}$ 의 용량이 한정적이지만서 비스율은 식(4), (5)로 주어지는 서비스율 $\gamma_{0, d}^{\prime}, \gamma_{1, d}^{\prime}$ 를 평균 도착율로 하는 Poission 프로세스로 근사화할 수 있다.

$$
\begin{gathered}
\gamma_{0, d}^{\prime}=\gamma_{0, d}\left(1-p_{0, d}\right) \\
\gamma_{1, d}^{\prime}=\gamma_{1, d}\left(1-p_{1, d}\right)
\end{gathered}
$$

첫 번째 단(state)에 있는 $\mathrm{K}$ 개의 파장은 $\mathrm{M} / \mathrm{M} / \mathrm{K} / \mathrm{K}$ 손 실모델로 나타낼 수 있으므로 Erlang's loss formula 에 의 해 손실률은 $\mathrm{K}$ 개의 파장이 사용될 확률이므로 식 (6)으 로 주어진다.

$$
p_{1}^{K}=\frac{\frac{\left(a_{1}^{\prime}\right)^{K}}{K !}}{\sum_{i=0}^{K} \frac{\left(a_{1}^{\prime}\right)^{i}}{i !}}, a_{1}^{\prime}=\frac{\gamma_{1}^{\prime}}{\mu}, \gamma_{1}^{\prime}=\gamma_{1, n}+\gamma_{1, d}^{\prime}
$$


두 번째 단에서의 손실률 $P_{W-K}$ 는 트래픽 $\gamma_{0}^{\prime}$ 의 손실 률인 $P_{0}^{W-K}$ 과 트래픽 $\gamma_{1}^{\prime \prime}$ 의 손실률인 $p_{1}^{W-K}$ 를 통해 식 (7)과 같이 구성된다.

$$
p_{W-K}=\frac{\gamma_{0}^{\prime}}{\gamma_{1}^{\prime \prime}+\gamma_{0}^{\prime}} p_{0}^{W-K}+\frac{\gamma_{1}^{\prime \prime}}{\gamma_{1}^{\prime \prime}+\gamma_{0}^{\prime}} p_{1}^{W-K}
$$

두 번째 단에는 선취권과 우회 방식이 적용된다. 우회 방식은 하나의 버스트가 출력포트 중 하나의 출력포트 로 우회될 확률 $\mathrm{p}$ 를 통해 규정된다. 클래스 0 버스트에 있어서 우회가 불가한 경우, 즉 우회확률 $\mathrm{p}$ 의 값이 0 인 상황에서는 W-K 의 파장이 모두 사용 중인 경우에 손실 이 발생하고, 반면에 우회가 가능한 경우, 즉 우회확률 $\mathrm{p}$ 가 1 인 경우에는 손실률이 $p_{0, d}$ 인 $V_{0, d}$ 버퍼로 입력되므 로 클래스 0 의 손실률은 식 (8)로 주어진다.

$$
p_{0}^{W-K}=\sum_{i=0}^{W-K} p_{i, W-K-i} \times\left[(1-p)+p \times p_{0, d}\right]
$$

클래스 1 버스트의 경우에는 모든 W-K 개의 파장이 클래스 1 버스트에 의해 점유되지 않은 경우에만 선취권 이 적용되어 클래스 0 에 의해 사용되고 있던 파장이 클래 스1 트래픽으로 이양된다. 모든 W-K 개의 파장이 클래 스1 트래픽에 의해 사용 중인 경우에는 우회가 발생한 다. 우회가 이루어진 경우에는 트래픽은 손실률 $p_{1, d}$ 를 갖는 버퍼 $V_{1, d}$ 로 우회되므로 클래스 1 버스트의 손실률 은 식 (9)로 주어진다. 식(8), (9)에서의 $p_{i, j}$ 는 정상상태 에서 $\mathrm{i}$ 개의 클래스 1 버스트와 $\mathrm{j}$ 개의 클래스 0 버스트가 존재할 확률을 나타낸다.

$$
p_{1}^{W-K}=p_{W-K, 0} \times\left[(1-p)+p \times p_{1, d}\right]
$$

그림 4는 W-K 개의 파장에 대한 상태천이도를 나타 낸다. 각각의 상태는 $\mathrm{i}$ 개의 클래스 1 버스트와 $\mathrm{j}$ 개의 클 래스0 버스트 $(i, j)$ 로 나타내며 $\mathrm{i}, \mathrm{j}$ 의 범위는 $0 \leq i \leq(W-K), 0 \leq j \leq(W-K)$

$0 \leq i+j \leq(W-K)$ 이다.
그림 4. 두 번째 단의 상태천이도

Fig. 4 State Transition Diagram for 2nd Stage

그림 4로부터 각 상태에서의 정상상태 관계식이 유도 된다. 각 상태에서의 관계식은 각 상태에서의 입력 흐름 (flow)과 출력 흐름(flow)은 동일하다는 흐름 보전 (conservation)에 근거한다. 따라서 상태 $(0,0)$ 에서의 관계 식은 식 (10)으로 주어진다.

$$
\left(\gamma_{1}^{\prime \prime}+\gamma_{0}^{\prime}\right) p_{0,0}=\mu\left(p_{1,0}+p_{0,1}\right)
$$

다른 상태이서의 관계식도 동일한 방식을 적용하여 도출되며 최종적으로 식 (11)의 조건을 부가하여 확률 $p_{i, j}$ 를 구한다.

$$
\begin{aligned}
& 1=\sum p_{i, j} \\
& 0 \leq i \leq W-K \\
& 0 \leq j \leq W-K \\
& 0 \leq i+j \leq W-K
\end{aligned}
$$

확률 $p_{i, j}$ 가 상태 방정식으로부터 구해지면 클래스 1 의 손실률 $p_{1}$ 과 클래스 0 의 손실률 $p_{0}$ 는 식 (12)와 (13)으 로 주어진다.

$$
p_{1}=1-\frac{\gamma_{1}^{\prime \prime}\left(1-p_{1}^{W-K}\right)+\gamma_{1}^{\prime}\left(1-p_{1}^{K}\right)}{\gamma_{1}}, \gamma_{1}=\gamma_{1, n}+\gamma_{1, d}
$$




$$
p_{0}=1-\frac{\gamma_{0}^{\prime}\left(1-p_{0}^{W-K}\right)}{\gamma_{0}}, \gamma_{0}=\gamma_{0, n}+\gamma_{0, d}
$$

$p_{1}$ 과 $p_{0}$ 로부터 클래스 1 과 클래스 0 간의 손실률 비율 은 식 (14)로 주어진다.

$$
\alpha_{1}=\frac{p_{0}}{p_{1}}=\frac{1-\frac{\gamma_{0}^{\prime}\left(1-p_{0}^{W-K}\right)}{\gamma_{0}}}{1-\frac{\gamma_{1}^{\prime \prime}\left(1-p_{1}^{W-K}\right)+\gamma_{1}^{\prime}\left(1-p_{1}^{K}\right)}{\gamma_{1}}}
$$

\section{$\mathrm{IV}$. 수학적 분석 결과}

그림 5는 $\gamma_{o d}=0.25 \gamma, \gamma_{o n}=0.25 \gamma, \gamma_{1 d}=0.25 \gamma$, $\gamma_{1 n}=0.25 \gamma, V_{o d}=2, V_{1 d}=2, h=2, \delta=0.1 L, W=4$ 의 조건에서 $\mathrm{K}$ 와 $\mathrm{p}$ 를 매개변수로 사용하여 버스트의 손실률을 입력률 $\rho$ 에 대하여 표시한 것이다.

그림 5 로부터 클래스 1 의 손실률 $p_{1}$ 은 $\mathrm{K}$ 가 증가함에 따라 감소함을 알 수 잇다. 이것은 $\mathrm{K}$ 가 증가함에 따라 클래스 1 트래픽이 첫 번째 단(state)에서의 서비스 기회 가 높아지기 때문이다. 반면에 클래스 0 의 손실률 $p_{0}$ 는 $\mathrm{K}$ 가 증가함에 따라 커지는 것을 알 수 있다. $\mathrm{K}$ 개의 파장 은 클래스 1 트래픽에 의해 전적으로 사용되므로 클래스 1 과 클래스 0 에 공통으로 사용되는 파장의 수 $\mathrm{W}-\mathrm{K}$ 는 감 소되어 클래스 0 의 서비스 기회가 낮아진다.

그림 5 로부터 클래스 1 에 의해 전적으로 사용되는 파 장이 없는 경우인 $\mathrm{K}=0$ 인 상황에도 서비스 차별화가 가 능한 것에 주목한다. 이것은 두 번째 단에서의 선취권 방 식에 의한 결과이다. 따라서 두 번째 단에서 선취권 방식 이 적용되지 않는다면 서비스 차별화가 불가하므로 선 취권 방식은 서비스 차별화를 실현하는 중요한 요소임 을 알 수 있다.

그림 5로부터 우회확률 $\mathrm{p}$ 가 증가하면 클래스 1 과 클 래스0의 손실률은 감소됨을 알 수 있다. 우회를 통해 블 록(block)된 버스트에 게 새로운 경로를 제공하므로 당연 히 기대할 수 있는 결과이다. 주목할 점은 클래스 1 과 클 래스 0 간의 손실률 차이가 우회확률 $\mathrm{p}$ 가 증가하면서 감 소된다는 점이다.

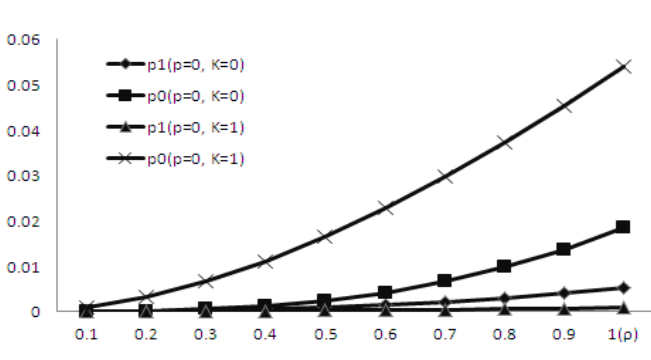

(a)

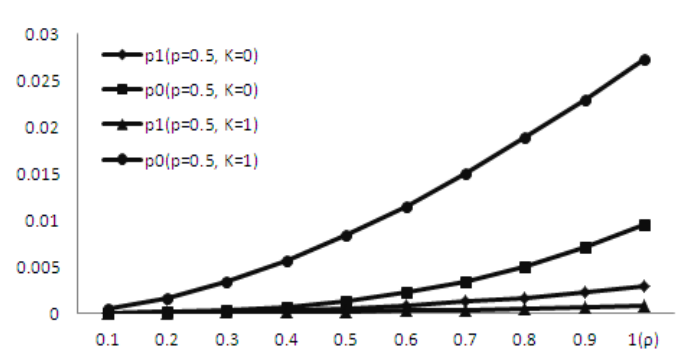

(b)

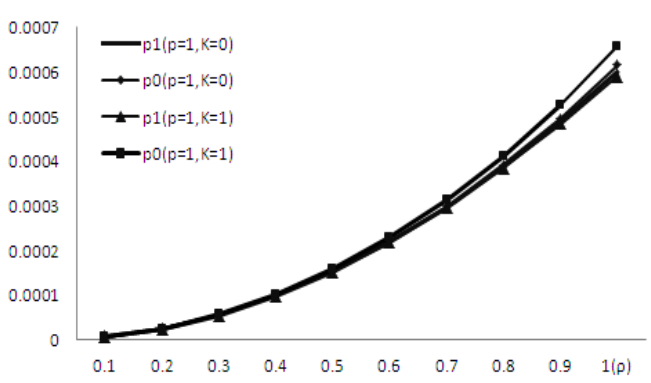

(c)

그림 5. 서비스 차별화 성능

(a) $p=0$ 인 경우의 손실확률 (b) $p=0.5$ 인 경우의 손실확률 (c) $p=1.0$ 인 경우의 손실확률

Fig. 5 The Performance of Service Differentiation (a) Loss probability for $p=0$ (b) Loss probability for $p=0.5$ (c) Loss probability for $p=1.0$

그림 6은 입력율이 0.9 이고 $\mathrm{K}=0$ 인 경우에 우회확률 $\mathrm{p}$ 에 대한 두 클래스의 손실률 차이를 나타낸다. 그림 6으 로부터 우회확률 $\mathrm{p}$ 가 증가함에 따라 손실률 차이는 감소 
된다. 이것으로부터 제안된 방식에서의 우회는 클래스 0 의 손실률을 낮추는데 효과적인 방식임을 알 수 있다.

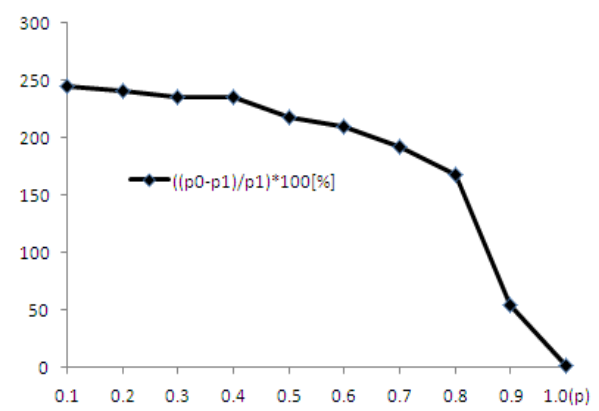

그림 6. 우회확률에 대한 손실률 $(\rho=0.9, \mathrm{~K}=0)$

Fig. 6 Loss Rate for Deflection Probability

그림 5와 6으로부터 class1에 더 많은 파장을 할애하 고 두 번째 단(stage)에 선취권을 적용하고 우회를 적용 하는 것을 특징으로 하는 제안된 방식은 광 버스트 스위 치 네트워크에서 서비스 차별화를 보장함을 알 수 있다.

그림 7은 섹션 3.2에서 기술한 비례적 서비스 차별화 알고리듬을 적용한 결과이다. 매개변수는 목표 손실률 비율은 $2, \mathrm{~W}$ 는 $4, \varepsilon$ 는 3 으로 설정한다.

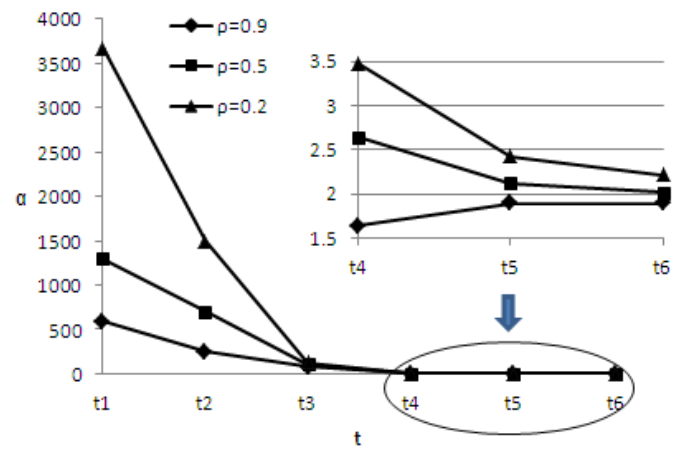

그림 7. 비례적 서비스 차별화 성능

Fig. 7 The Performance of Relative Differentiation

$\mathrm{t} 1$ 에서 $\mathrm{K}$ 의 값은 알고리듬에서 제시한 대로 3 으로 설정된다. 그림 7 로부터 $\mathrm{t} 1$ 에서의 손실률 비율은 목표 값인 2에서 크게 벗어나 있다. 측정된 손실률 비율은 목 표-비율 정확도 계수인 $\varepsilon$ 를 벗어나므로 클래스 0 의 손실 률을 낮추기 위해 $\mathrm{t} 2$ 에서 $\mathrm{K}$ 의 값은 2 로 감소된다. $\mathrm{t} 3$ 에서
비록 손실률 비율이 낮아졌지만 여전히 목표-비율 정확 도 계수 범위를 벗어나 있으므로 $\mathrm{t} 4$ 까지 $\mathrm{K}$ 의 값이 감소 된다. $\mathrm{t} 4$ 에서는 손실률 비율이 목표-비율 정확도 계수 범 위안이므로 선취권, 우회, 의도적 폐기 방식이 적용되어 목표치 2로 근접함을 알 수 있다.

\section{V. 결론}

광 버스트 스위치 네트워크에서 $\mathrm{QoS}$ 차별화를 달성 하는 방식을 제안했고 분석적 큐잉 모델이 도출되었고 도출된 모델에 근거한 수치해석이 수행되었다. 수치해 석 결과를 통해 제안된 알고리듬은 광 버스트 스위치 네 트워크에서 손실률 차별화가 이루어짐을 알 수 있었다. 특히, 수학적 성능분석을 통해 우회방식이 우선순위가 낮은 트래픽에 있어서도 매우 효과적으로 손실률을 낮 추는 것으로 확인되었다. 손실률과 관련된 서비스 차별 화 방식에 근거한 비례적 서비스 차별화 방식이 제안되 었다. 제안된 방식은 우회방식과 선취권 방식을 적용하 면서 우선순위가 높은 트래픽에 할당되는 파장의 수를 동적으로 가변시키는 것을 특징으로 한다. 수치해석을 통해 제안된 방식을 통해 비례적 서비스 차별화가 가능 함을 알 수 있었다.

추후의 연구과제로는 트래픽의 손실률을 낮추면서 동시에 목표 손실률 비율을 고도의 정확도를 통해 달성 시키는 정교한 비례적 차별화 알고리듬을 개발하는 것 이다.

\section{참고문헌}

[ 1 ] C. Qiao and M. Yoo, "Optical Burst Switching(OBS) A New Paradigm for an Optical Internet," Journal of High Speed Networks, Vol. 8, No. 1, pp. 69-84, 1999.

[2 ] J. Y. Wei, J. L. Pastor, R. S. Ramamurthy, and Y. Tsai, "Just-in-time Optical Burst Switching for Multi-wavelength Networks," Proc. 5th Int. Conf. Broadband Commun., Vol. 18, pp. 2019-2037, Dec. 2000

[3] C. Qiao, "Labeled Optical Burst Switching for IPover-WDM Integration," IEEE Commun. Mag., pp. 
104-114, Sept., 2000.

[4] A. Detti, V. Eramo, and M. Listanti, "Performance Evaluation of a New Technique for IP Support in a WDM Optical Network: Optical Composite Burst Switching (ODBS)," J. Lightwave Technol., Vol. 20, pp. 154-165, Feb., 2002.

[5] R. Ramaswami and K. N. Sivarajan, "Routing and Wavelength Assignment in All-optical Networks," IEEE/ACM Trans. Networking, Vol. 3, pp. 489-500, Oct., 1995.

[6] A. Bononi, G. A. Castanon, and O. K. Tonguz, "Analysis of Hot-potato Optical Networks with Wavelength Conversion," J. Lightwave Technol., Vol. 17, pp. 525-534, Apr., 1999

[ 7 ] I. Chlamtac et al., "CORD: Contention Resolution by Delay Lines," IEEE J. Select Areas Commun., Vol. 14, pp. 1014-1029, June, 1996.

[ 8 ] M. Baresi, S. Bregni, A. Pattavina, and G. Vegetti, "Deflection Routing in Full-Optical IP Switching Networks," Proc. IEEE ICC 2003.

[9] Y. Chen, H. Wu, D. Hu, and C. Qiao, "Performance Analysis of Optical Burst Switched Node with Deflection Routing," Proc., IEEE ICC 2003.

[10] Q. Zhang, V. M. Vokkarane, J. P. Jue, and B. Chen, "Absolute QoS Differentiation in Optical Burst-Switched Networks," IEEE J. Select Areas Commun., Vol. 22, pp. 1781-1795, Nov., 2004.

[11] C. Dovrolis and P. Ramanathan, "Proportional Differentiated Services: Delay Differentiation and Packet Scheduling," IEEE/ACM Transactions on Networking, Vol. 10, No. 1, February 2002.

[12] M. Yoo, C. Qiao, and S. Dixit, "QoS Performance of Optical Burst Switching in IP-Over-WDM networks," IEEE J. Select Areas Commun., Vol. 18, pp. 2062-2071, Oct., 2000.

[13] Y. Chen, M. Hamdi. D. H. K., and Tsang, "Proportional QoS over OBS networks," Proc. IEEE GLOBECOM 2001, Vol. 3, pp. 1510-1514, Nov. 2001.

[14] Y. Chen, M. Hamdi. D. H. K. Tsang and C. Qiao, "Proportional QoS Provision: A Uniform and Practical Solution," IEEE ICC 2002, Vol. 4, pp. 2363-2367,
May 2002.

[15] Chee-wei Tan, Mohan Gurusamy, and John Chi-Shing Lui, "Achieving Proportional Loss Differentiation Using Probabilistic Preemptive Burst Segmentation in Optical Burst Switching WDM Networks," GLOBECOM'041, 2004.

[16] H. C. Cankaya, S. Charcranoon and T. S. El-Bawab, "A Preemptive Scheduling Technique for OBS Networks with Service Differentiation," Proc. IEEE Globecom 2003, November 2003.

[17] C.-F.Hsu, T.-L.Liu, and N.-F. Huang, "On the Deflection Routing in QoS Supported Optical Burst-Switched Networks," Proc. of INFOCOM, New York, June, 2002.

$$
\text { 저자소개 }
$$

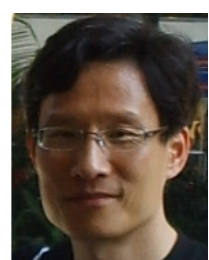

백정훈(Junghoon Paik)

1986년 2월 : 한양대학교

$$
\text { 전자공학과(공학사) }
$$

1988년 2월 : 한양대학교 전자공학과(공학석사)

1999년 8월 : 한양대학교 전자공학과(공학박사)

2011년 8월 2012년 8월 : 미국 California State University, Fullerton Visiting Scholar 2002년 9월 현재 : 동아방송예술대학 방송통신과 교수

※관심분야: 방송통신망 성능 분석 